\title{
Possible organosedimentary structures on Mars
}

\author{
Vincenzo Rizzo' and Nicola Cantasano ${ }^{2}$ \\ ${ }^{1}$ Earth Science Department, Florence University, Via L. Repaci snc, 87036 Rende (Cs.), Italy \\ ${ }^{2}$ National Council of Research, I.S.A.Fo.M. U.O.S., Via Cavour 4/6, 87036 Rende (Cs.), Italy \\ e-mail:n.cantasano@isafom.cs.cnr.it
}

\begin{abstract}
This study, using the Microscopic Imager (MI) of NASA Rover Exploration Mission's (REM) 'Opportunity', aims to explain the origin of laminated sediments lying at Meridiani Planum of Mars, and of the strange spherules, known as blueberries, about which several hypotheses have been formulated. To this purpose, images of the sedimentary textures of layers and fragments captured by REM have been analysed; sediments that NASA has already established as 'pertinent to water presence'. Our study shows that such laminated sediments and the spherules they contain could be organosedimentary structures, probably produced by microorganisms. The laminated structures are characterized by a sequence of a thin pair of layers, which have the features of skeletal/agglutinated laminae and whose basic constituents are made by a partition of septa and vacuoles radially arranged around a central one. The growth of these supposed organosedimentary masses is based on the 'built flexibility' of such a basal element; it may be a coalescing microfossil formed by progressive film accretion (calcimicrobe), in a variety of geometrical gross forms, such as a repeated couplet sequence of laminae or domal mass and large composite polycentric spherule, both in elevation. The acquired structural and textural data seem to be consistent with the existence of life on Mars and could explain an origin of sediments at Meridiani Planum similar to that of terrestrial stromatolites. The Martian deposits, probably produced by cyanobacterial activity, and the embedded blueberries could represent a recurrent and multiform product of colonies with sheath forms, resembling in shape those of the fossil genus Archaeosphaeroides (stromatolites of Fig Tree, South Africa).

Received 11 June 2009, accepted 24 June 2009, first published online 28 August 2009
\end{abstract}

Key words: blueberries, calcimicrobes, cyanobacteria, life, Mars, stromatolites.

\section{Introduction}

The possibility of life on Mars, even in a fossilized state, opens up new horizons for the human colonization of the Solar System. The presence of sedimentary layers, probably produced by the metabolic activity of microorganisms living under extreme environmental conditions, indicates that primordial forms of life can arise from very little, and could then be more widespread than we can imagine. It is even more amazing to make a comparison with ancient terrestrial forms of life, and to consider the relevant cultural implications this relationship implies.

The hypothesis of the presence of life on Mars was advanced in 1984, when American researchers found a small meteorite, weighing $8 \mathrm{~kg}$ and $20 \mathrm{~cm}$ in diameter, on the Allan Hills in the Transantarctic Range. Initially the fragment, named ALH84001, was assigned as a 'diogenite': a kind of igneous meteorite, a sliver of the Vesta asteroid. Finally, in 1993, David McKay, a NASA biochemist, declared that the meteorite was, in fact, a Martian fragment which dated back 4.5 billion years, and he proposed its biological origin (McKay et al. 1996).

Some years later, McKay's hypothesis was refuted by other NASA research teams and in 2001 was definitively put aside for several reasons: the identification of Polycyclic Aromatic Hydrocarbon (IPA) on the meteorite was regarded as environmental contamination; the micro-rings on its surface seemed so small as to be completely unlike any form of terrestrial bacteria; the signs of loadstone incorporated in the meteorite's carbonatic matter were artificially reproduced in laboratory and, therefore, they were considered as inadequate evidence (McKay et al. 1998).

NASA's latest Rover Exploration Mission (REM, employing rovers 'Opportunity' and 'Spirit'), has captured, from 2004 until now, the Mars landscape of Meridiani Planum and Gusev Crater, recording macroscopic (PanCam) and microscopic (MI) imagery. The pictures of the Mars outcrops brings forth once again an old problem, further emphasized by the presence on the Martian ground of several blue-coloured spherules, which Steve Squyres, team leader of NASA's mission, nicknamed 'blueberries' (Fig. 1). Squyres himself, in NASA's press conference of March 2, 2004, advanced two hypotheses: the Aeolian-sedimentary origin of the subcrops of Meridiani Planum and the concretionary nature of the spherules (Squyres et al. 2004).

Later, other scientists (McCollom \& Hynek 2006) suggested the hypothesis of a volcanic origin of the sediments 


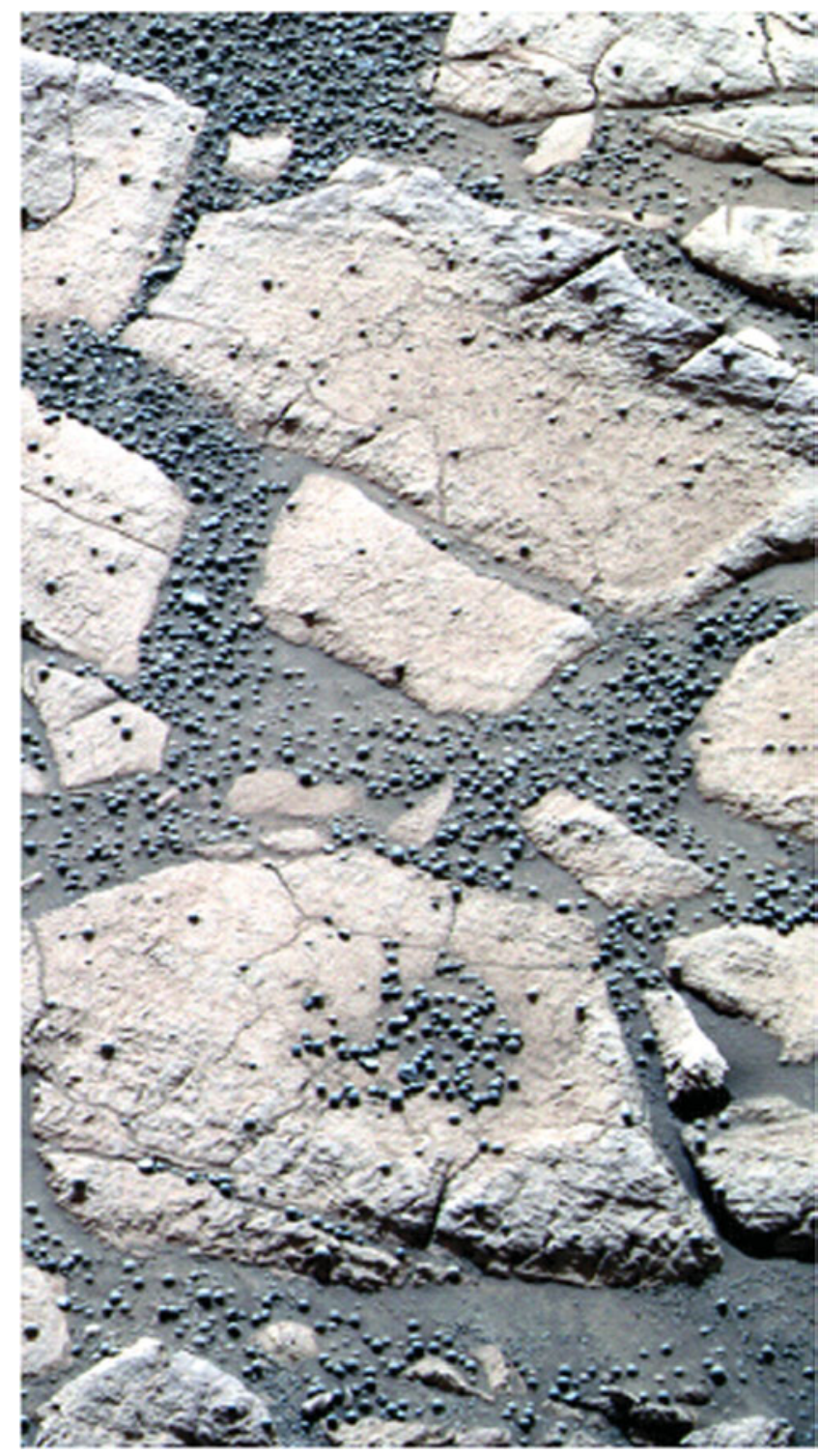

Fig. 1. Panoramic picture (PanCam) of spherules known as 'blueberries'.

and spherules, but this interpretation was superseded by NASA's concretional theory (Squyres et al. 2006) after studies of the chemical composition of the spherules indicated the presence of haematite, a mineral whose basic constituents grow in aquatic environments. Moreover, the substratum was made up of silicate and sulphate minerals, while the rocks in which the spherules were embedded appeared highly laminated, so that their presence inside the layers was considered as the concretional product coming from diagenetic processes.

Other authors (Catling 2004; Chan et al. 2004; Coleman et al. 2005), following up Squyres' concretional theory, made a comparison between the Martian blueberries and similar forms present on Earth such as pisolits, oolits and other similar formations. Also advanced was the attractive theory that these spherules could have been raised from an impact between Mars and a meteorite, involving deposition from a ground-hugging turbulent flow of rock fragments, salts, sulphides, brines and ice produced by the impact (Knauth et al. 2005).

McKay's theory, consistent with a biological origin of the carbonate globules covering the Martian meteorite ALH 84001, resurfaced in 2005. Spanish researchers at the Madrid Astrobiology Center, and later American groups, put forward the proposal that the strange spherules on Meridiani Planum could be related to a community of chemolithoautotrophic bacteria still living on Earth in acid environments enriched by iron minerals (Parro et al. 2005; Jepsen et al. 2007). Recently, other authors have found further evidence of life on Mars by detection of methane and formaldehyde (Onstott et al. 2006; Schulze-Makuch et al. 2008). The biological theory was also supported by Italian researchers (Caiola \& Billi 2007); they supposed that some terrestrial organisms, from the cyanobacteria group and similar to the genus Chroococcidiopsis, could be adapted to Martian conditions. Finally, in July 2008, NASA admitted that the geological conformation of the Martian surface encountered by the space probes 'Opportunity' and 'Spirit' was consistent with the presence of water in remote ages. NASA declined to give an opinion about the biological origin of the blueberries, but stated that the search for life on Mars would be the main goal of the next missions in 2009.

This study aims to describe the structures of layers and blueberries in the area of Meridiani Planum in order to understand their debated origin.

\section{Materials and methods}

The study undertakes a systematic analysis of MI shot by Athena, a camera mounted on the NASA Mars Exploration Rover (MER) 'Opportunity', and of panoramic photos shot by a wide-angle camera (PanCam) mounted on the same rover. The field of view of both instruments is $1024 \times 1024$ pixels in size. The images in this study, captured by MI, are monochromatic because there is a single broad-band filter mounted on the MI. The MI optics provide $\pm 3 \mathrm{~mm}$ depthof-field at $30 \mu \mathrm{m} /$ pixel sampling. The working distance is $63 \mathrm{~mm}$ from the front of the lens barrel to the object plane. In this condition the field of view is about $3 \mathrm{~cm}$ in size and the texture of bodies smaller than $100 \mu \mathrm{m}$ cannot be visualized. There are several images of regards polished surfaces, about $7 \mathrm{~cm}$ in diameter, prepared by MER's circular Rock Abrasion Tool (RAT); this tool is able to grind about $5 \mathrm{~mm}$ of sediments near the midpoint, tapering toward its border.

As regards to the methodological approach; first, various forms of microfossils have been individualized and classified, and the most-often occurring kinds identified. The structure of the laminated sediments and the nature of the spherical bodies embedded amongst the layers of the surface sediments have been successively analyzed, focusing both on polished surfaces and on exposed ones; structural and morphological relationships were used to assume their origin. In this context, 
fragments and eroded bodies were useful in understanding internal structure.

\section{Results}

The study of a selected set of amplified MER MI images shows the presence of objects which have traits of prevalently microfossil-like artefacts resembling early life stages (Fig. 2). They include spatially structured chambers and septa somewhat spirally organized (Fig. 2(m), (n), (o), (p)), bodies showing a 'from interior' growth Fig. 2(a), difficult to explain by physico-chemical processes, perfect holes (Fig. 2(u) bordered by collars resembling terrestrial foraminifera Fig. 2(c), sheathed forms Fig. 2(g), complex perfect shapes and texture (Fig. 2(h) and (r)), hyaline film and substances denoting occurrence of non-lithic matter (Fig. 2(g), (i), (o)), organized in structured forms including ring-tube (Fig. 2(e), (o) and (t)) and helicoidal/spiralled forms (Fig. 2(i), (j), (m), (n), (o), (p)), typical of probably both marine and terrestrial (Fig. 2, respectively (c) and (d)) environmental facies, and some of which remind us of our Early Cambrian biofacies (Fig. 2(f) and (g)). Many of these microfossils, especially those in Fig. 2(e), (g), (l), (n), (p), together with a large variety of bluish spherical bodies known as blueberries, are very common and widespread.

The structural and morphological study of a large set of blueberries and related fragments show that they are different from each other, having a variety of forms and dimensions, and are not homogeneous in their internal structure (Figs 3 and 4).

Spherule diameter is generally less than $5 \mathrm{~mm}$ while the smallest recognizable spherules are of about $0.1-0.3 \mathrm{~mm}$ and have a regularly spaced cell structure (examples are given in Figs 2, 3, 4 and 5), of which the laminated sediments are made. These spherules, in spite of their small dimensions, are clearly distinguishable by their shiny darker (almost metallic) appearance (Fig. 2(p); Fig. 3(n); Fig. 4(f) and (g); Fig. 5(d)). They are set over the central depression (Ri) of a whitish ring array (BS), which are layered; or they are set over a cell of comparable dimension, of which the darkish layer is structured (Ri on BSr; Fig. 4(f) and (g); Fig. 5(i)); or they are set over a hyaline film (Fig. 3(a)). These small and apparently uniform balls, having an almost perfect spheroidal and blackmetallic appearance, are different from the biggest spherules known as blueberries. In fact, blueberries show varied and irregular shape with a spheroidal tendency, and all represent composite structures made by BS, Ri and BSr type elements (Figs 3 and 4).

In particular, as regards the observed shape of the blueberries (Fig. 3), in places spherules are in close contact, and somewhere their shape is adapted along lines of contact (Fig. $3(b)$ ), whereas in other cases they show conical or bi-conical forms (Fig. 3(c), (s) and (u)), peduncles (Fig. 3(c) and (i)), holes (Fig. 3(e)), a coalescing tendency and more complex forms which may result from a structured sheet rolling-up action and a multi-centre growth (Fig. 3(m-o)). The spherule surface shows the coalescence of elementary structures of Ri and BS type (some of them indicated by white arrows in Fig. 4 ), and in some cases by regular or irregular internal cell partitions (Fig. 4(c)). The variety of shapes and external structures (each one different) could be seen as the result of different constructions built from further smaller constituents (including the cell partition, whose dimensions are about $0.1 \mathrm{~mm}-0.3 \mathrm{~mm}$ ). The BS structure is observed on the spherule surface, has a dimension of about $1 \mathrm{~mm}$, and comprises a sheet of a radial array of 5-10 cells around a central cell, this last occupied by an Ri element. As seen in Fig. 2(1) the BS structures are coalescing, and as displayed in Fig. 4, they develop mutual interconnections between the Ri centres. The growth of the spherule thus represents the result of both a rolling-up of BS structure and a radial polycentric array (rarely mono-centric). The described structure is reflects an ideal, perfect spherule; but very often the observed anomalies, such as having one or more structural centres that are more developed than others, give a body asymmetry or indicate a new developing internal body (examples are given in Fig. 2(a)). A clear example of the rolling-up tendency can be seen in Fig. 3(v), where on the right side and on its apical sector there is evidence of a developed rolling sheet; the change of spherule diameter corresponding to a circular step (of about $0.2 \mathrm{~mm}$ ) could be also interpreted as a consequence of such rolling sheet, whose occurrence one can directly observe in Fig. 3(g) and (q).

As consequence of small cell dimensions, such structures cannot be appreciated without optical amplifications. They become evident on eroded fragments, where we can see the internal differences between structural constituents. Obviously, on polished surfaces (by MER RAR), we cannot observe the spatial structure but only a labyrinthiform pattern.

Observations on internal parts of the spherules confirm the previously described structure. Fig. 4 shows nodal points (Ri) radially interconnected by spokes (Fig. 4(a) and (b)). In Fig. 4(b) it is evident that radial spaces have different dimensions; in this way the spherules could enlarge asymmetrically, or develop a plurilobate body. Fig. 4(p) shows an evident anomaly and the presence of a spiral sector (white circles). In Fig. 4(c) a section of a spherule shows radial sub-partition, where cell and septa are interconnected having labyrinthiform patterns (not random, but still distributed around central points), separated by an elongate array both circular and linear (dot lines). This structure is very common and, as a consequence, the spherule fragments break along plane surfaces or flake along the rolling-up sheet (Fig. 4(b), (c) and (e) are examples of this breaking); conchoid fracturing is secondary. This structure is also evident when observing more 'fresh' bodies (Fig. 4(f), (g), (h)), where the structural elements Ri and BS are easily recognizable.

As we have seen, spherules relate to the sediments which are structurally connected by peduncle or radial channels. Often, especially in the smaller bodies, they show radial mutual interconnection, a tract of the internal structure of the layers (Figs 4 and 5). Fig. 4 contains a set of pictures (Fig. 4(i), (l), (m), (o) and (p)) showing the relationship between spherules and surrounding sediments and 

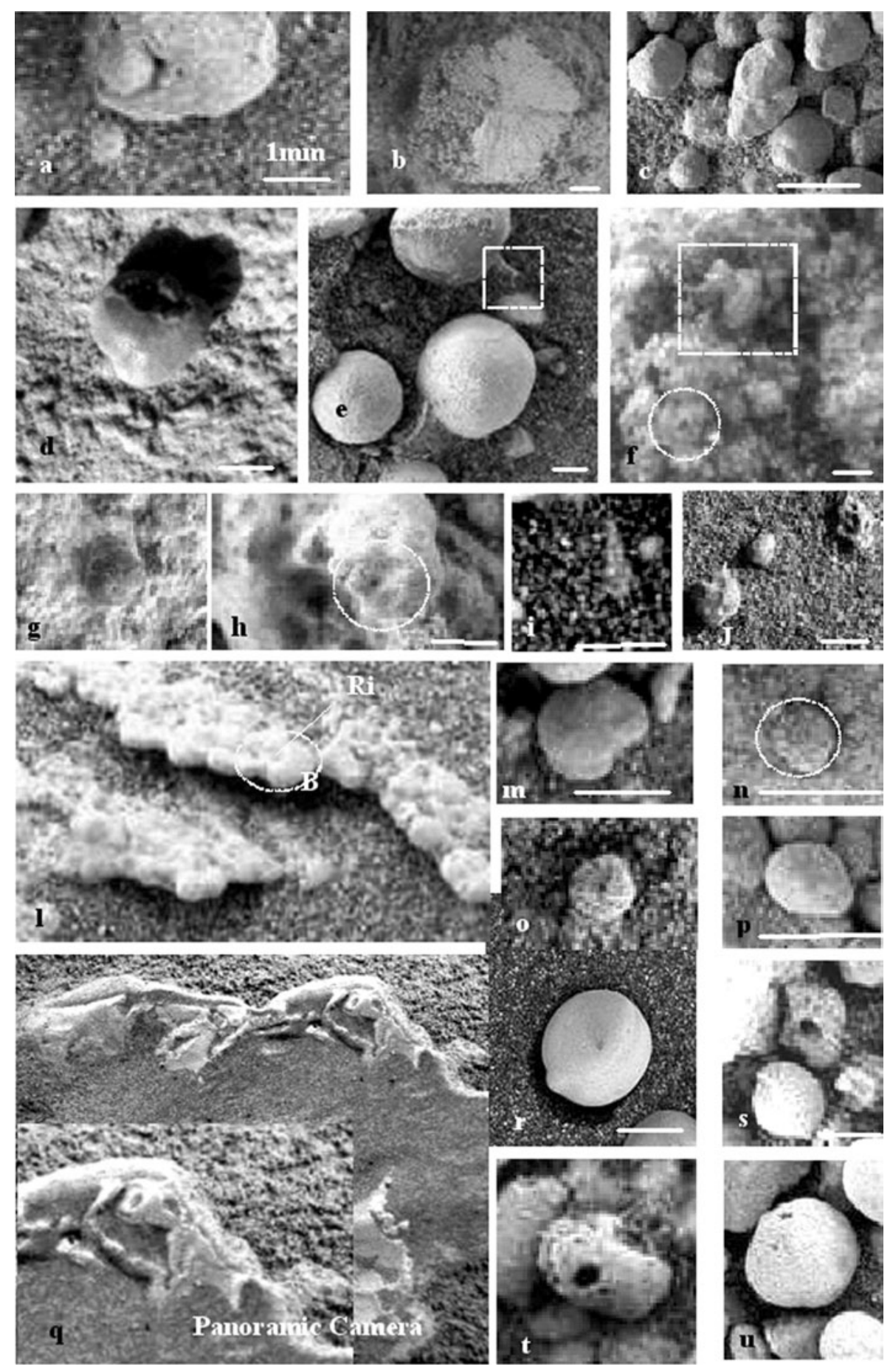

Fig. 2. Morphological and structural evidence of the existence of life on Mars. Amplified Mars Exploration Rovers imagery showing a sampled set of objects resembling biological products or terrestrial microfossils (white bars represent $1 \mathrm{~mm}$ ): (a) a form composed of two different bodies, the bigger one having a small collar and a lateral deformed tear, covering another spherical body and denoting an expanding, not concretionary, process; (b) a reticulate regular radial form, not compatible with sedimentary processes; (c) microfossil resembling a terrestrial benthonic foraminifer, having a distinctive form and a collar; (d) an irregular form having a prominent collar, seeming of vegetal origin; (e) on the top and on the left of central spherule there are respectively a segmented tube and a shapeless mass, both made by hyaline substance (white squares); (f), (g), forms remembering terrestrial Early Cambrian or Precambrian microfossils (prominent cones marked by white squares in pictures (f); (f), (h) and (n) show repeated (colonial?) structures made by vacuoles and septa, radially arranged around a central cell (white circles); (i), (j), (m), (n), (o) and (p) are other forms resembling terrestrial microfossils having circular/helicoidal/spiral array, or having a distinctive shape and septa/vacuoles, some of which are hyaline ((i) and (o)), and somewhere covered by a transparent film); (1) structure characterized by a planar coalescing of microfossils, these last (BS; white circles) having partitions arranged around a central depression (Ri). (q) a large strange fossil (the convex central part is covered by sediments). 

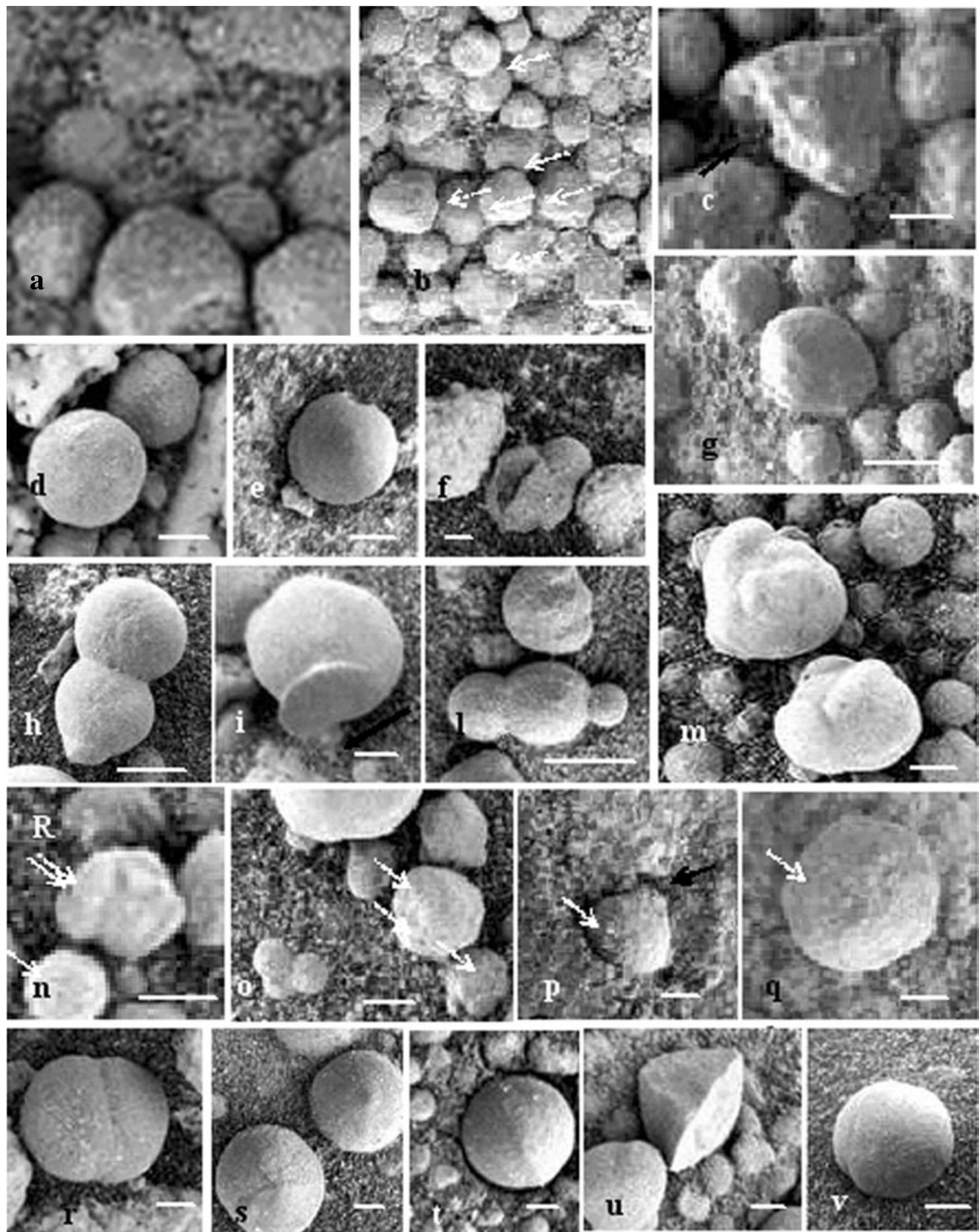

Fig. 3. Morphology of blueberries (scale bars represent $1 \mathrm{~mm}$ ). The spherule in the pictures are: (a) the smallest appreciable on Microscopic Imager imagery are metallic and dark in appearance and are set over central hole of radial structure (white arrows show other examples in pictures (n-q)) formed on a hyaline film (the film is covering all the bodies in pictures (a), (b), (c) and (g); see also Fig. 7); (b) ordered and all inter-growing (arrows show the adjacent contact points); (c) conical, bordered by cells and connected to the base by a peduncle (black arrows); (d) almost perfect, but showing a spiral cell array on the top; (e) showing hemispherical enlargement; (f) cleaved (resembling Fig.2(a)); (g) showing an enrolled cell array; (h) coalescing; (i) fixed to the soil by peduncle (black arrow); (l) growing in-axis as a 'rowspherule' forms, and having unitary tracts (a linear cell string on the top and along the long axis); (m) 'plurilobate', showing both a tendency to enlarge polycentrically and to roll up; (n) 'polylobate'; (o) growing in multi-axes as 'multi-spherule'; (p) having a montgoifierlike shape (arrow shows a prominence from where the spherule was attached to the soil before displacing by rover Rock Abrasion Tool); (q) as in picture (g), but with a polycentric tendency; (r) growth as bi-spherule; (s), (u) as conical; (t) marked by a rim (see Fig. 6) or by a circular step; (v) showing a rolling-up growth. 

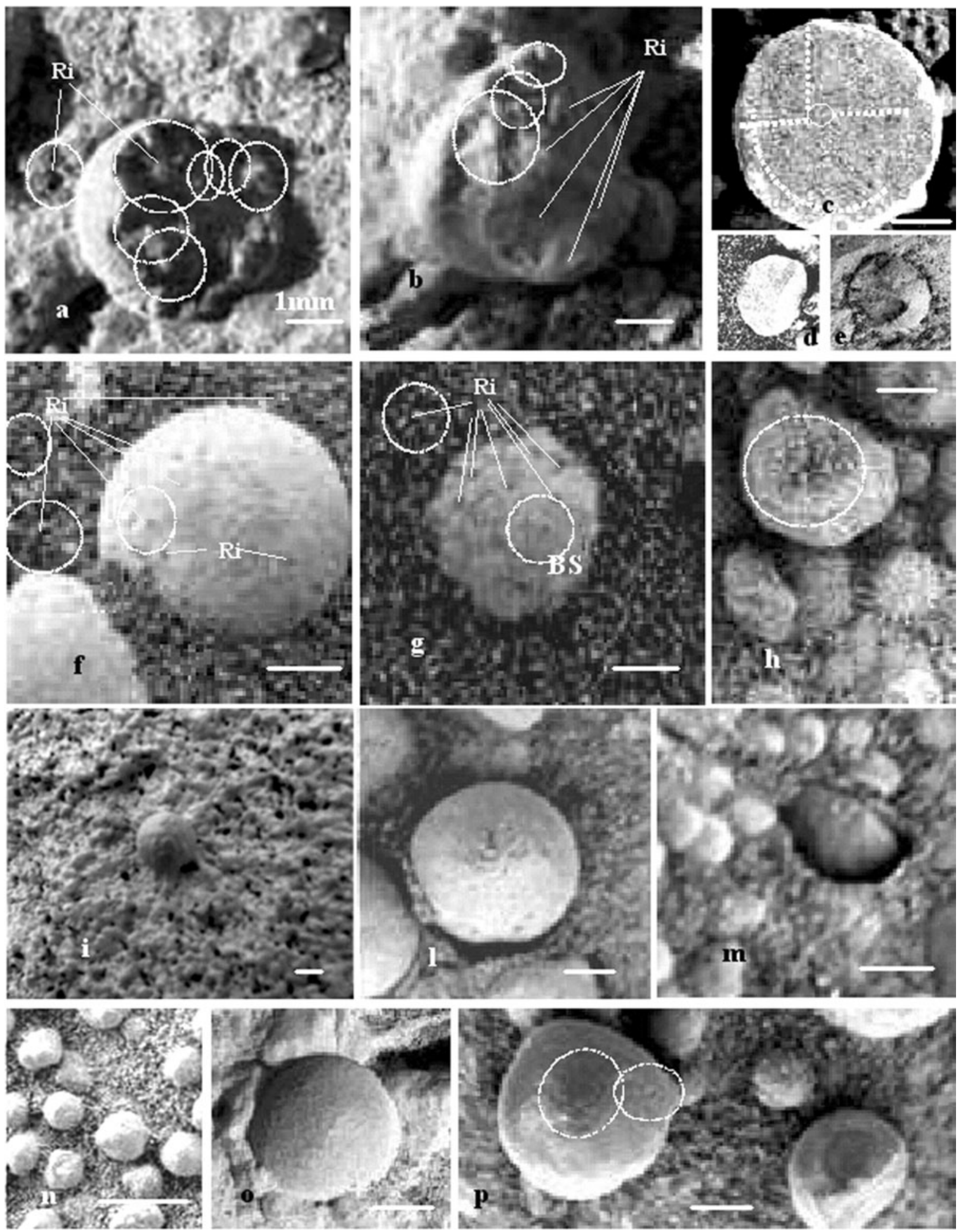

Fig. 4. Internal structure of blueberries in relation to the sediment where they are found (scale bars represents $1 \mathrm{~mm})$. (a), (b), (f), (g), (h) Polycentric structure characterized by a radial array of connections between small darker spherule Ri (circles show radial array of spherules and layers); (c) in section, the same structure shows body partitions in sectors marked by internal cell arrays (white lines show two such sectors separated by linear array of elongated cell files); this distribution denotes a non-homogeneous body where linear array produces planes of weakness along which the spherule could break following slice or planar surfaces ((d) and (e)); (i), (o) examples of radial connection between spherules and sediments (compare with Fig. 4(m) and to Fig. 7 (clockwise images); (1), (m), (p) examples of mutual interconnection between spherules and layers: in pictures $(1)$ and $(\mathrm{m})$ the structure of the layer opens on the spherules, while in picture $(\mathrm{p})$ it encircles the spherule; both the opposite tendencies denote that they were synsedimentary; (p) two recurrent irregularities on cell array of the spherule (white circle on the left shows the beginning of a spiral array, while on the right the anomalous array is totally separated and circular, and is a germ of a polylobate spherule). 


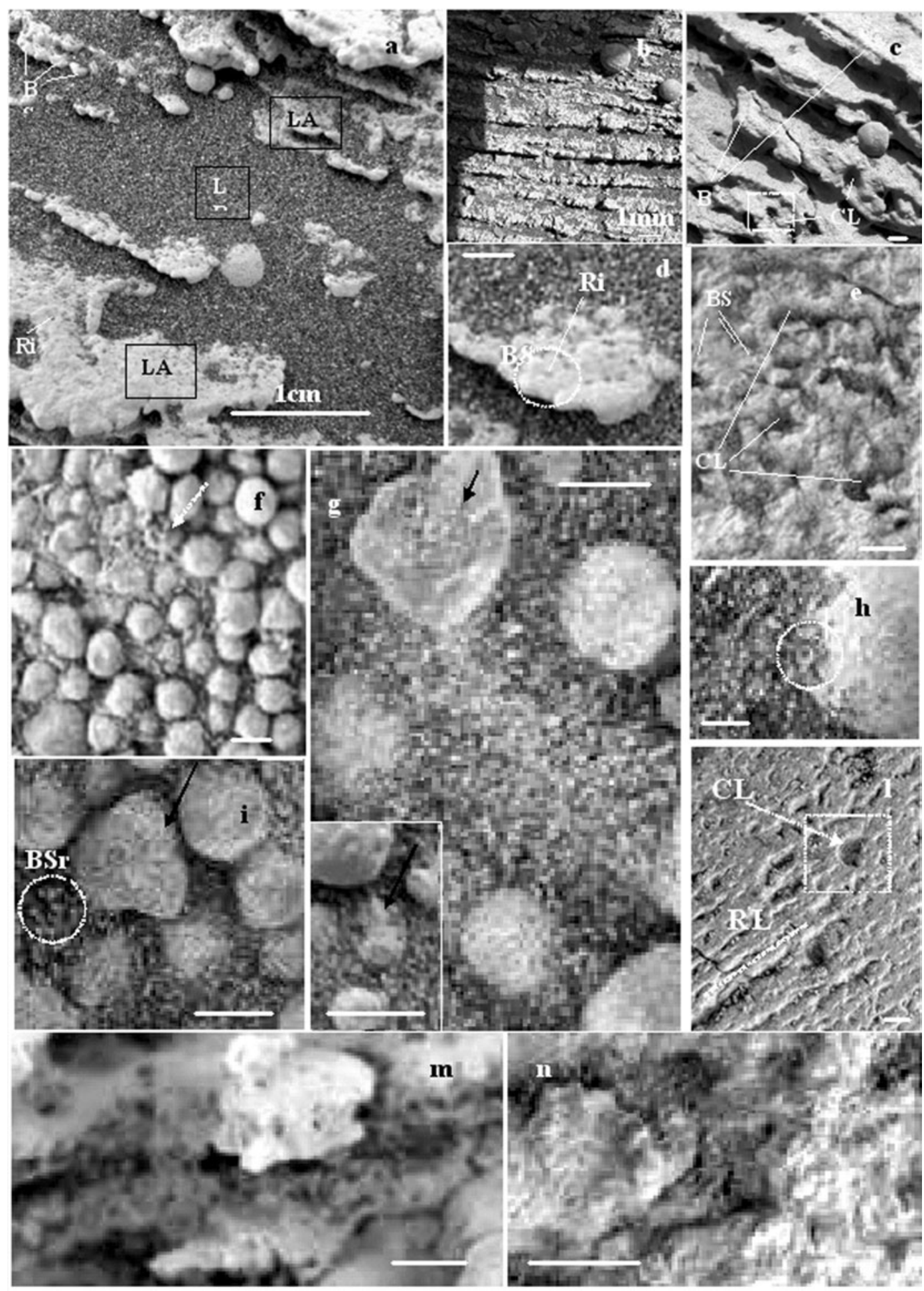

Fig. 5. Microstructure of layers and accretionary films (scale bar where not marked represents $1 \mathrm{~mm}$ ). (a), (b), (c) Sediments composed of a sequence of a couple of laminae (LA/LB); laminae are composed of a carpet of coalescing microfossils (BS); (d) microfossils are characterized by a circular array of vacuoles, having a dark spherule up in the centre (Ri). (d), (i) Circular array is both on LA (BS) and in places on LB (BSr). (e) LB is made by a fine and dark - at times disordered - silt, where often one can observe a structural circular array as above (SBr). In spite of such basilar homogeneity the surface of LA shows different structures: irregular closed-CL, or linear-LR passing to undulatory or hemispherical (e) and (l). (f), (g), (h), (i) In places, both over LA and LB one observes a hyaline film, reproducing the Sb and $\mathrm{SBr}$ shape and sketching microfossils (black arrows in pictures (I) and (g)); (n) this film shows a gradual passage to a whitish biogenic accretion, which maintains the shape of the cell array and forms the described BS structures. (h) The circle evidences the exact contact of film with a previous structure. $(\mathrm{m})$ an interlayered LB-type structure shows its internal spatial array made by radial connections, that resemble the internal structure of spherules; in LB they are more open (characterized by large spaces in communication and open channels). 
proving their syngenetic origin (or a contemporary adjusting growth).

The structures of the laminated sediments under observation comprise an almost-regular sequence of a couple of thin layers (LA/LB), where one (LA) is coherent and whitish (resembling an organogenic calcareous layer), and the other (LB) is incoherent and dark (resembling an equigranular silt composed of grains of femic rocks). The ratio of $\mathrm{LA} / \mathrm{LB}$ thickness varies from $1 / 1$ to $1 / 4$ or more; in places the pattern is of a couple of repeated close LAs separated by a thicker LB. The thickness sequence $\mathrm{LA} / \mathrm{LB} / \mathrm{LA} / \mathrm{LB}$, in some of the cases examined, then becomes indicative of $1 / 1 / 1 / 4$ (Fig. 5(a), (b) and (c)). The laminae show a regular submillimetre thickness, denoting a very calm depositional environment.

The layer LA is, to a large extent, composed of overlapping coalescing microfossils, forming a white lamina. Microfossils are constituted by the basilar structure (BS), having a dimension of about $0.5-1 \mathrm{~mm}$. The BS structure is formed by a radial array of globular partitions (as in the case shown in Fig. 5(d)), that correspond to a set of septa and vacuoles located around a central one, on top of which an unstable small dark spherule (like those of Fig. 5(d)) is normally set; in places the BS structure shows spiral patterns, and on the top of central site there is a spheroidal prominence (like those seen in Fig. 2(n) and (p)). As a consequence of such peculiar and very widespread biogenic texture forming the laminae, the margin of layer LA is generally typically hemmed (Fig. 2(1); Fig. 5(a)). On the polished (by RAT) surface of LA we can observe a variety of different geometrical arrangements of BS (Fig. 5): forming flanked linear paths and interposed channels (structure RL type, in Fig. 5(1)); having two close linear arrays separated by a more distanced space (Fig. 5(c)); forming the wall of cave cones, in places encircling a spherule; and forming regular or irregular closed spaces, separated by walls of several BS linear array (structure CL in Fig. 5(e) and (1)).

The layer LB in places shows a disordered texture, made by loose basaltic silt (Squyres et al. 2004); in other cases such texture seems to become ordered, assuming a different aspect by forming BS analogous patterns and showing a net of septa and vacuoles of similar or smaller dimension $(0.2-0.5 \mathrm{~mm})$; in this case the BS structure shows a more evident central cell covered by a similar dark sheen (metallic in appearance) spherule (BSr; Fig. 5). The BSr structure is characterized by a net of radial interconnections between the central cells, resembling the polycentric structure of spherules and other massive LA structures; but as a consequence of its high elastic-organic content, the fossilized layers show a large extent of open space, forming channels (Fig. 5(m)).

In places we can observe the presence of hyaline film, covering all the bodies (Fig. 3(a), (b), (c), (g) and (m); Fig. 4(h); Fig. 5(f), (g), (h), (i) and (n)); this film is structured in ordered holes whose pattern is similar to the BS, Ri and BSr structures (Fig. 5(f)). The film structure shows a tendency to a coincident overlapping with those of underlying bodies; an example of the latter is given in Fig. 5(h), where we can observe the perfect coincidence of $\mathrm{Ri} / \mathrm{BSr} / \mathrm{BS}$ structures (white circle). Over the film we can see the presence of sparse small Ri-like spherules (Fig. 4(h)) and, in places, the appearance of hyaline microfossils (Fig. 5(i) and (g)). In Fig. 5(n) we can observe a gradual passage from the hyaline film to a whitish veil $(\mathrm{V})$, in places increasingly thick and extended to form a lamina, with structures of SB type; this is a fundamental step in forming the couplet of layer LA/LB and spherules (Figs 5, 6 and 7).

This process is accompanied by the growth of the described spherules and other individual bodies (SF). Their spatial array show that they could be lonely and in open order or closely approached, in this case resembling a layer of rounded grains, sometimes coalescing. When they are small they are often surrounded by radial septa of the SBr structure from where they grow denoting their structural belongings to the LA/LB sequence (Fig. 7). In this case the structure BSr of layer LB, becomes less evident because of the dimension of radial septa in comparison to those of spherules.

A set of structures in elevation (SF1) should be considered separately because of their peculiarities (Fig. 2(g); Fig. 8(c), (f), (g), (h), (l), (m) and (o)). In fact they are sheath structures found contained on the top of a hyaline cup, and seem to be hard and more deeply rooted (generally remaining outstanding on RAT-polished surfaces, as in Fig. 8(c), (f), (g), (h) and (m)); overall they do not show the described polycentric/ labyrinthiform structure for SF bodies but a small, dark engraved dome of about $0.5-1 \mathrm{~mm}$, resembling in colour the smallest described metallic spherules.

\section{Discussion}

A first relevant question, looking at several of the MI Opportunity REM images, is the presence on Mars of putative biogenic matter. In fact, it is rightly and commonly thought that it is impossible to prove a biological origin based only on images at the microscopic/submicroscopic scale. Nevertheless, the structures we reported and discussed from the MI have a dimensional range of about $0.1 \mathrm{~mm}-1 \mathrm{~cm}$ : a scale where complex structures are evident and distinctive. As an example, on Earth, palaeontologists have no problems in assigning a biological origin to phoraminifera, usually identifying and classifying different species based only on their shape.

It is known that microbolites are organosedimentary deposits caused by the sediment-binding and/or carbonate precipitation activity of microbes (Burne \& Moore 1987), whose products include stromatolites, thrombolites, dendrites, and oncoids, and their identification is based on mesoscopic texture (Dupraz \& Strasser 1999; Wacey 2009); they are fossil products that are mineralic in composition but generated by microbial activity. The biological origin of fossil-like microscopic objects can be established by demonstrating that they possess a suite of traits that are unique to life, traits that as taken together are shared by fossils and living organisms but not by inanimate matter; in this sense Precambrian microfossils are true fossils (Barghoorn \& Tyler 1965; 

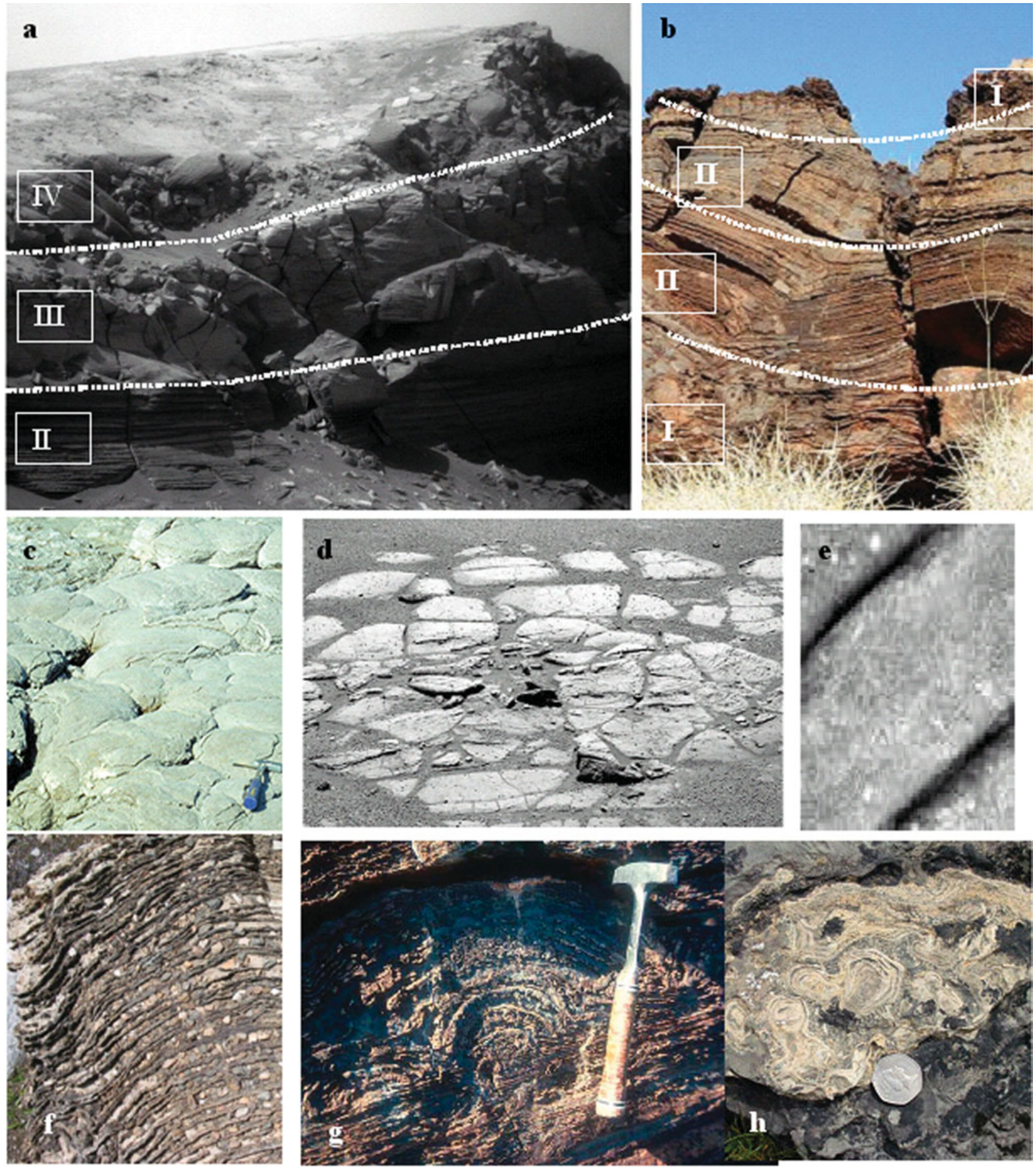

Fig. 6. Comparison between Mars sediments and terrestrial stromatolite structures: (a), (b) Martian laminated sequence (on the left) in comparison with a South African outcropping (on the right); the latter shows a vertical passage from a more detrital interval (at the base) to a more bio-concretional one (on the top), referred to as the classic four stages of sea level regression. A tabular-domed structure of living Australian stromatolites (c) that could explain the origin of disjointed structures observed on the Martian surface (d). (e) a strange structure on the surface of Mars, resembling a 'tabular wall' structure of stromatolite type. (f), (g), (h) Pictures of terrestrial stromatolites structures, very similar to those of Mars sediments.

Barghoorn \& Schopf 1965). In the case of microbolites, their microbial origin is supported by growth forms which are typical of bioaccretion but which lack the regular geometry expected of physiochemical precipitates, by the presence of 'trapped grains', by the occurrence of microbial remains, by clotting to peloidal micrite composition and by the occurrence of fenestrae apparently corresponding to primary voids (Camoin et al. 1999). 


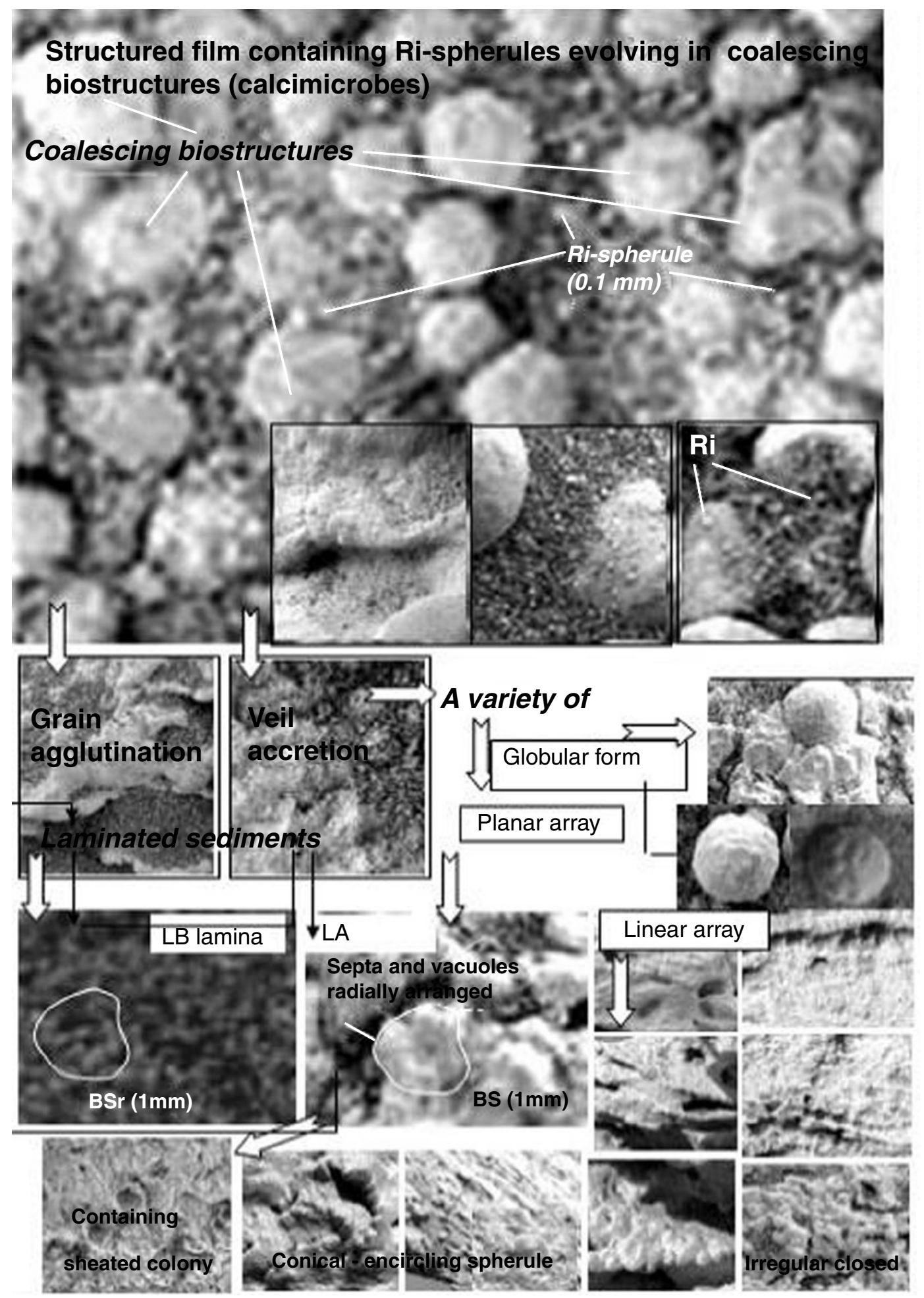

Fig. 7. Bio-accretionary process, starting with hyaline film development, forming skeletal/agglutinated laminae and spherules SF. On the top left: an LB layer showing structures of BSr type.

More generally, the observed structural features, such as preferred orientation indicating a role in the formation of biofabric, biological morphology related to presence of sheaths, hollows and other microfossil-like tracts, traces of products of metabolic activity, several steps of biologylike component and multicomponent assemblage, folding of films, fracturing morphology, etc., together suggest the possible existence of community life on Mars.

It is already accepted that in the area of Meridiani Planum there is an outcrop of highly laminated sedimentary formation containing many spherules, known as blueberries, whose origin is poorly understood, with hypothetical explanations 

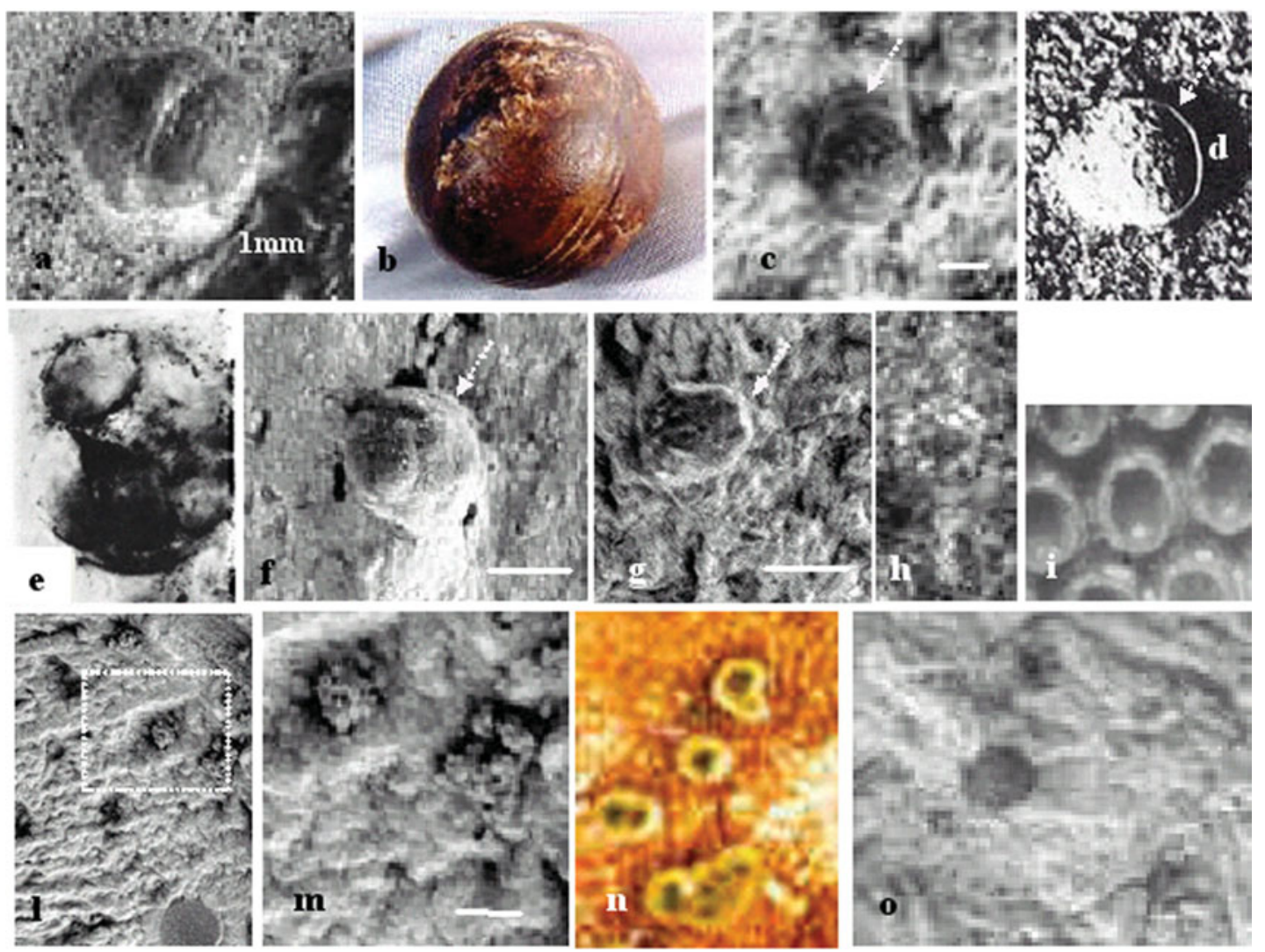

Fig. 8. Comparison of Martian and terrestrial structural elements of colonies (scale bars without indication represent $1 \mathrm{~mm}$; Mars images are referred to as LA lamina type and to RAT polish surfaces; terrestrial image are without scale bar). The Martian spherule (a) finds a parallel with the enigmatic ball of a Precambrian sedimentary iron mine (b). Terrestrial sheathed colonies of cyanobacteria, genus

Archaeosphaeroides (d), (e), show similar shape to the Martian ones (f) and (g). Others pictures of stromatolite terrestrial sheath colonies (South Africa) resembling the structure present on LA lamina of Martian laminated sediments (pictures (i) and (n) in comparison respectively to $(\mathrm{h}),(\mathrm{m})$ and $(\mathrm{o}))$.

incongruent with the structural data described in this work. In this context, the microscopic and macroscopic laminated sediment structures at Meridiani Planum are, as already described, similar to those of terrestrial stromatolites, and they are characterized by typical features of biogenic outcroppings, such as 'low symmetry' and 'complex morphology’ (Wacey 2009).

For example, as regards layer thickness, the typical Mars asymmetric sequences $\mathrm{LA} / \mathrm{LB}$, whose common ratio is $1 / 4$, is very similar to some terrestrial stromatolites (Fig Tree, South Africa; examples are given in Fig. 5(a), (b) and (c)). With regard to complex morphology, the LA layers show a variety of structures made by several different microfossil arrays and types (RL and CL; BS and BSr); likewise, the LA surface shows great diversity in microfossil array. Similarity to terrestrial stromatolite structures is suggested (for example, compare Fig. 5(l) with Fig. 6(g); Fig. 5(e) with Fig. 6(h); Fig. 5(c) with Fig. 6(f)). Similarly, the thickness of LA layers is sub-millimetre $(0.5-1.5 \mathrm{~mm})$ and comparable to those of terrestrial stromatolites; besides, observation and data on the couplet LA/LB strongly resembles the skeletal lamina and the agglutinated layer of stromatolite formation. The most important processes involved in the formation of stromatolite laminae on the Earth are carbonate precipitation and grain trapping, whose products are agglutinated laminae (formed by grain-trapped accretion) or skeletal laminae (formed by recognizable microfossils, called calcimicrobes, or by precipitated isopachous micro-lamina). Similarly to the stromatolite colonies, we can observe the presence of hyaline films and a process of gradual accretion to form calcimicrobes (examples are given in Figs 5 and 7). It is known that calcimicrobes played a leading role in the formation of stromatolites in the Palaeozoic period (Nose et al. 2006). The skeletal framework of this type reveals an intimate intergrowth of tabular to domical structures and thick planar to pillar-like calcimicrobial crusts (Manten 1971). Pope et al. (2000) noted that stromatolites with isopachous laminae texture and self-replicating morphologies are primitive and common in Achaean and Palaeoproterozoic carbonates. As the recognized Mars microfossils have larger dimensions, in comparison with the dimensions of known microbes on the Earth, it has been supposed that the structure BS could represent the more complex structure of smaller ones not distinguishable in MI imagery. In support of our hypothesis it should be noted that structures similar to the basic BS and Ri ones described here, and with similar dimensions, were observed at 


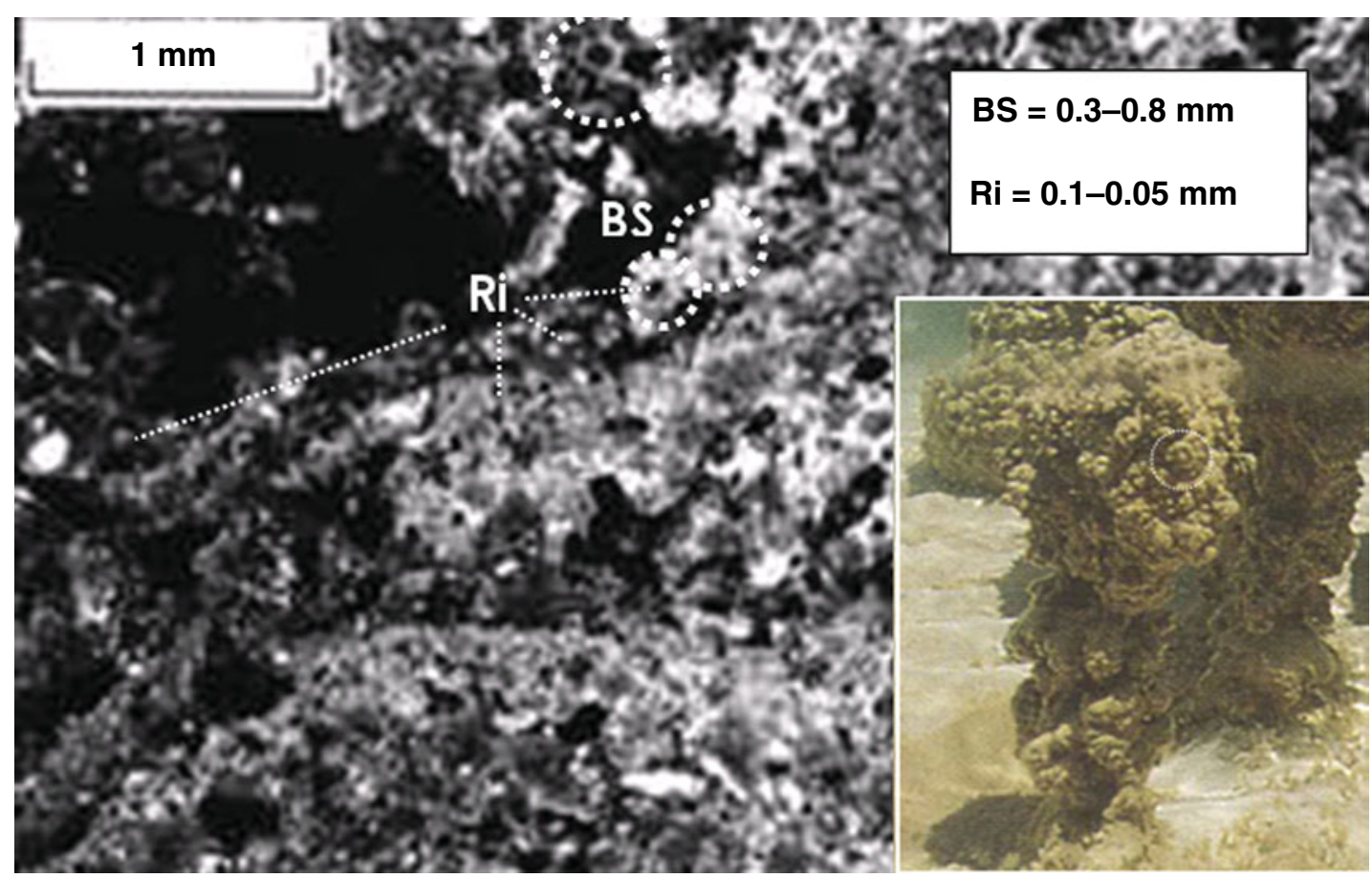

Fig. 9. Pictures of terrestrial stromatolites showing the same basic 'BS' and 'Ri' structures at different scales: microscopic sections showing structures having similar dimensions to those described for Martian laminated sediments (main picture); a living Australian columnarstromatolite showing a morphology made by plates agglomerates of similar structure (inset right).

different scales in samples of terrestrial stromatolites (Fig. 9). Nevertheless, we assume that some of them are probably not related to colonial association and indicative of benthonic facies.

However, typical sheathed colony structures were identified and they have parallels with the structures of terrestrial cyanobacteria (Fig. 8(c), (f), (h) and (m) in comparison, respectively, to Fig. 8(d), (e), (i) and (n)); the same bacteria that built stromatolites. In particular, the shape of same sheathed colonies is reminiscent of, apart from dimensions, those of the genus Archaeosphaeroides, found in South Africa (Schopf \& Barghoorn 1967; Fig. 8(e) in comparison with Fig. 8(f)). These archaeobacters, belonging to the cyanobacteria group, a subclass of Coccogoneae, have a spheroidal body and are characterized by coccoidal forms. Such unicellular prokaryotic bacteria, as they are known, are able to live in extreme environmental conditions.

As regards occurrence of minerals derived from biological activity, we should note the presence of haematite inside the laminated sediments of Mars; this is another typical peculiarity of terrestrial stromatolite, resulting from cyanobacterial metabolism, and is a mineral component that could have facilitated the fossil preservation of bacteria sheath (Morris et al. 1998). Many other morphologies of the LA surface are similar to stromatolite-like structures, and terrestrial similarity was also found with regards to the 'blueberries'.

In fact, the described structures of the spherules are not congruent with the suggested concretionary origin of blueberries (Squyres et al. 2004). Such structures are different from those characterizing ooids, oolites (Van Houten \&
Bhattacharrya 1982) and other similar concrete materials (Chan et al. 2004; Chan et al. 2005); it is known that these last consist of concentric homogeneous layers made by a variety of matter, generally grown around a pre-existent body (Bums $\&$ Burns 1975). Discrepancy between concrete structures and the apparent uniform internal structure of blueberries was noted by other authors who hypothesized that their diagenetic concretion formed over the bedrock in stagnant groundwater (Schneider et al. 2007). On this basis they supposed that the amount of contained haematite (still not exactly established), should be considered in relation to the supposed inclusive, replacement or displacement mechanisms of concretions. The genesis of blueberries was poorly understood, but it could well be explained by looking at their shape and structures. Following our observations, spherules are not homogeneous, and show peculiar structures and a variety of shapes that could be a potential sign of their biogenic origin. A variety of shapes may denote a large flexibility on the spatial array of smaller, basic elements, these last having the same recognizable and common texture. In this sense, finding similarities on the basis of rounded shape may be irrelevant: there are parallels in the tendency to make not only sheet laminae but also conical or closed bodies. Structural relations to the sediments containing spherules denote that they could pertain to the recognized stromatolite formation and be syngenetic with them. As a curiosity, blueberries may have similarities with the bigger 'Sferules of Ottosdal' (West Transvaal, South Africa), that are described on internet sites as metallic spherules of bluish colour, having an inexplicable origin and found inside a sedimentary mine of Precambrian 
Age (Fig. 8(b)), and as bluish spherules found in stromatolite formations of Archaeospheroides (Schopf \& Barghoorn 1967).

Similitude between Terrestrial and Martian stromatolites includes not only microscopic structures but also macroscopic ones. Comparing Fig. 6(a) and (b) we can observe a similar typical vertical evolution of stromatolite sediments due to the regression of sea level, passing from the more coarse/detritus-based layers present at the base (interval I) towards the finer and laminated intervals in the upper part (interval II); while at the top (interval III) the outcrops show a columnar, polygonal surface (compare Fig. 6(c) and (d)). The primitive structure and the abundance of organic matter, which characterize the higher intervals of a stromatolite sequence, both probably represent the predisposing factors that have favoured, due to the particular environmental conditions, the observed disjointed block structure at the surface (Fig. 6(d)). In this context we can observe that the crust (interval IV shown in Fig. 6(b)), which represents the last stage of a regressive stromatolite sequence, is practically absent on outcrops of Meridiani Planum.

\section{Conclusions}

In conclusion, on Mars there is evidence of the presence of fossils. The sedimentary high laminated outcroppings at Meridiani Planum show structures that could be of organogenic origin. The morphology of the sedimentary laminae is so regular in thickness that it is probably more related to biological activity than to a physico-chemical origin under a calm hydrodynamic environment; low symmetry and complex morphology both testifying their potential biogenic origin. Sedimentary structures of laminated sediments, on both large and microscopic scales, are similar to terrestrial stromatolite structures, whose occurrence seems to be 'tabular, non-columnar, flat-laminated'; in addition, in places we can observe 'undulatory and laterally linked' stromatolite structure types. Similarity was also found as regards morphology of sheeted cyanobacteria colonies. The occurrence of haematite is another relevant factor and denotes a genesis in lowacid water, as may be expected on Mars, considering the large amount of carbon anhydrite $\left(\mathrm{CO}_{2}\right)$ and sulphur anhydrite $\left(\mathrm{SO}_{2}\right)$ (Moore 2004).

The morphological and structural variety of spherules, known as blueberries, are associated with these putative organosedimentary sediments, where they grow sustained by a possible biogenic activity. They could be seen as the result of enrolled sheets of BS structure, where the Ri centres are interconnected, forming both a radial and a polycentric structure. The dimensions of described basilar structures of sediments, such as the smallest dark spherule and the radial array ( $\mathrm{Ri}$ and $\mathrm{SB}$ ), are not comparable with the dimensions of known microbes. It is reasonable, therefore, to suppose that they are colonies and represent complex bodies of more elementary structures.

Parallels between Meridiani Planum sediments and fossil stromatolites could also explain the occurrence of large polygonal and collapsed blocks outcropping on the surface; these could in fact be interpreted as a consequence of 'flat laminated to tabular/slight domed' structures typical of a stromatolite regressive sequence. In this context, the absence of a gradual passage to the upper microbolite crust may denote a rapid change of environmental conditions.

At the same time, the occurrence of hyaline forms and the growth of similar BS-type structure by clots, globular masses in elevation or by sheets and films covering pre-existent bodies highlights not only similarities, but also differences with the actual environment of terrestrial stromatolites.

These are doubts and hypotheses that could be resolved by future NASA missions dedicated to proving the existence of life on Mars.

\section{Acknowledgement}

We thank Gian Gabriele Gori (Int'1 Research School of Planetary Sciences, University of Pescara, D'Annunzio), Daniela Billi (Dept. Biology, University of Rome, Tor Vergata), Carmen Argondizzo (Director of Linguistic Centre, University of Calabria) and Aniello Barone (National Council of Research I.S.A.Fo.M. U.O.S. Rende, Cosenza) for their review and input on this manuscript.

We gratefully acknowledge Professor J. William Schopf (Dept. of Earth and Space Science, University of California) for allowing use of photographs Fig. 6(g) and Fig. 8(e). We acknowledge, indeed, the successful efforts of the National Aeronautics and Space Administration Mars Exploration Rover team for their images, which have provided the basis for comparing Martian results with Terrestrial analogues.

\section{References}

Barghoorn, E.S. \& Schopf, J.W. (1965). Microorganisms from the Late Precambrian of Central Australia. Science 150, 337-339.

Barghoorn, E.S. \& Tyler, S.A. (1965). Microorganisms from the Glunflint chert. Science 147, 563-577.

Bums, R.G. \& Burns, V.M. (1975). Mechanism for nucleation and growth of manganese nodules. Nature 225, 130-131.

Burne, R.V. \& Moore, L.S. (1987). Microbolites: organosedimentary deposits of benthic microbial communities. Palaios 2, 241-254.

Caiola, M.G. \& Billi, D. (2007). Chroococcidiopsis from Desert to Mars. (Book Series). Cellular Origin, Life in Extreme Habitats and Astrobiology. Algae and Cyanobacteria in Extreme Environments, Vol. 11, pp. 553-568. Kluwer Academic Publishers, Dortrecht.

Camoin, G.F., Gautret, P., Montaggioni, L.F. \& Cabioch, G. (1999). Nature and environmental significance of microbialites in quaternary reefs: the Thaiti paradox. Sediment. Geol. 126, 271-304.

Catling, D.C. (2004). On Earth, as it is on Mars? Nature 429, 707-708.

Chan, M.A., Beitler, B., Parry, W.T., Ormö, J. \& Komatsu, G. (2004). A possible terrestrial analogue for haematite concretions on Mars. Nature 428, 731-734.

Chan, M.A., Bowen, B.B., Parry, W.T., Ormö, J. \& Komatsu, G. (2005) Red rock and red planet diagenesis: Comparisons of Earth and Mars concretions. Geol. Soc. Am. 15(8), 4-10.

Coleman, M.L., Hubbard, C.G., Mielke, R.E. \& Black, S. (2005). Chemical and Isotopic Characterization of Waters in Rio Tinto, Spain, shows 
possible origin of the Blueberry Haematite Nodules in Meridiani Planum, Mars. American Geophysical Union, Fall Meeting.

Dupraz, C. \& Strasser, A. (1999). Microbolites and micro-encrusters in shallow coral bioherms. Middle to Late Oxfordian, Swiss Jura Mountains. Facies 40, 101-130.

Jepsen, S.M., Priscu, J.C., Grimm, R.E. \& Bullock, M.A. (2007). The potential for lithoautotrophic life on Mars: application to shallow interfacial water environments. Astrobiology 7(2), 342-354.

Knauth, L.P., Burt, D.M. \& Wohletz, K.H. (2005). Impact origin of sediments at the Opportunity landing site on Mars. Nature 438, 1123-1128.

Manten, A.A. (1971). Silurian reefs of Gotland. Dev. Sedimentology 13, $1-539$.

McCollom, T.M. \& Hynek, B.M. (2006). A volcanic environment for bedrock diagenesis at Meridiani Planum on Mars. Nature 438, 1129 1131.

McKay, D.S., Gibson, E.K. Jr., Thomas-Keprta, K.L., Vali, H., Romanek, C.S., Clemett, S.J., Chillier, D.F., Maechling, C.R. \& Zare, R.N. (1996). Search for past life on Mars: possible relic biogenic activity in Martian meteorite ALH84001. Science 273, 924-930.

McKay, G., Mikouchi, T., Schwandt, C. \& Lofgren, G. (1998). Fracture fillings in ALH84001. Feldspathic glass: carbonatic and silica. $29^{\text {th }}$ Annual Lunar and Planetary Science Conference held March 16-20, 1998 in Houston, Texas. LPI Contribution No. 1998, Abstract no. 1944

Moore, J.M. (2004). Blueberry fields for ever. Nature 428, 711-712.

Morris, P.A., Allen, C.C., Gibson, E.K., McKay, D.S. \& Thomas-Keprta, K. (1998). Re-examination of the Warrawoona group fossils (Towers Formation, Western Australia, 3,3 to 3,5 GA): analogs of Mars meteorite fossils? 29 $9^{\text {th }}$ Annual Lunar and Planetary Science Conference held March 16-20, 1998 in Houston, Texas. LPI Contribution No. 1998, Abstract no. 1496.
Nose, M., Schmid, D.U. \& Leinfelder, R.R. (2006). Significance of microbialites, calcimicrobes and calcareous algae in reefal framework formation from the Silurian of Gotland, Sweden. Sediment Geol. 192(3-4), 243-265.

Onstott, T.C., McGown, D., Kessler, J., Sherwood Lollar, B., Lehmann, K.K., \& Clifford, S.M. (2006). Martian CH4: Sources, Flux and Detection. Astrobiology 6(2), 377-395.

Parro, V. et al. (2005). Instruments development to search for biomarkers on Mars: terrestrial acidophile, iron-powered chemiolithoautotrophic communities as model systems. Planet. Space Sci. 53(7), 729-737.

Pope, M.C., Grotzinger, J.P. \& Schreiber, B.C. (2000). Evaporitic subtidal stromatolites produced by in situ precipitation: textures, facies associations and temporal significance. J. Sediment Res. 70(5), 1139-1151.

Schneider, A.L., Mittlefehldt, D.W., Gellert, R. \& Jollif, B. (2007). Compositional constraints on ematite-rich spherule (Blueberry) formation at Meridiani Planum, Mars. Proc. Lunar Planet Sci. Conf. held March 12-16, 2007 in League City, Texas. LPI Contribution No. 1338, XXXVIII 1941 pdf.

Schopf, J.W. \& Barghoorn, E.S. (1967). Alga-like fossils from the Early Precambrian of South Africa. Science 156, 508-512.

Schulze-Makuch, D., Fairén, A.G. \& Davila, A.F. (2008). The case for life on Mars. Int. J. Astrobiol. 7, 117-141.

Squyres, S.W. et al. (2004). The Opportunity Rover's Athena Science Investigation at Meridiani Planum, Mars. Science 306, 1698-1703.

Squyres, S.W. et al. (2006). Planetary science: bedrock formation at Meridiani Planum. Nature 443, 1709-1714.

Van Houten, F.B. \& Bhattacharrya, D.P. (1982). Phanerozoic oolitic ironstones - Geologic records and facies model. Annu. Rev. Earth Planet. Sci. 10, 441-457.

Wacey, D. (2009). Early Life on Earth: A Practical Guide, pp. 1-274. Springer, Berlin. 